\title{
On the Reliability of Real Measurement Data for Assessing Power Quality Disturbances
}

\author{
Alexandre Brandao Nassif \\ Hydro One Inc.,Toronto, ON, \\ Canada
}

\section{Introduction}

Power quality assessment is a power engineering field that is first and foremost driven by real data measurements. All the power quality assessment applications rely on results from real data processing. Take as an example the art of harmonic filter design, which is an engineering field notoriously known for relying on simulation-based planning; in this technical assessment, data recordings are indirectly used for finding the frequency response (or $R-X$ plots) of the system impedance that is/are in turn used to determine the filters' tuning frequencies (Kimbark, 1971).

With so much reliance on the acquired data, the quality of such has become a very sensitive issue in power quality. An imperative action is to always employ high-resolution recording equipment in any instance of power quality analysis. Nevertheless, high-resolution equipment does not guarantee data usefulness because the measured data may be inherently of very low energy in a variety of ways. Therefore, to investigate such cases and to propose methods to identify useful data were the motivations for this research. This chapter proposes methods for data selection to be used in two applications where the reliability issue is crucial: the power system impedance estimation and the interharmonic source determination.

\subsection{The network harmonic impedance estimation}

Network impedance is power system parameter of great importance, and its accurate estimation is essential for power system analysis at fundamental and harmonic frequencies. This parameter is deemed of being of great importance for a variety of power system applications, such as evaluating the system short-circuit capacity, or defining the customer harmonic limits (Kimbark, 1971)-(IEEE Std. 519-1992). Several methods have been proposed to measure the network harmonic impedance and are available in literature. In this chapter, the transient-based approach is used to demonstrate the data selection methods. In the transient-based approach, the network impedance is conventionally calculated by using (Robert \& Deflandre, 1997)

$$
Z_{e q}(h)=-\Delta V(h) / \Delta I(h),
$$


where $\Delta V(h)$ and $\Delta I(h)$ are the subtraction in frequency domain of one or more cycles previous to the transient occurrence from the corresponding cycles containing the transient disturbance. The objective of this chapter is not to promote the use of the transient-based approach for determining the network harmonic impedance, nor is it to explain the method in detail. The reader is encouraged to consult (Robert \& Deflandre, 1997) for details. In this application, the level of accuracy of such estimation can be supported by a set of indices, which are (but not limited to) the quantization noise in the data acquisition, the frequency resolution, the energy levels, and the scattering of the results obtained from the data.

\subsection{The Interharmonics measurement}

Interharmonics are spectral components which frequencies are non-integer multiples of the supply fundamental frequency. This power quality event represents the target of the second application of the proposed reliability criteria. Diagnosing interharmonic problems is a difficult task for a number of reasons: (1) interharmonics do not manifest themselves in known and/or fixed frequencies, as they vary with the operating conditions of the interharmonic-producing load; (2) interharmonics can cause flicker in addition to distorting the waveforms, which makes them more harmful than harmonics; (3) they are hard to analyze, as they are related to the problem of waveform modulation (IEEE Task Force, 2007). The most common effects of interharmonics have been well documented in literature (IEEE Task Force, 2007), (Ghartemani \& Iravani, 2005)-(IEEE Interhamonic Task Force, 1997), (Yacamini, 1996). Much of the published material on interharmonics has identified the importance of determining the interharmonic source (Nassif et al, 2009, 2010a, 2010b). Only after the interharmonic source is identified, it is possible to assess the rate of responsibility and take suitable measures to design mitigation schemes. Interharmonic current spectral bins, which are typically of very low magnitude, are prone to suffer from their inherently low energy level. Due to this difficulty, the motivation of the proposed reliability criteria is to strengthen existing methods for determining the source of interharmonics and flicker which rely on the active power index (Kim et al, 2005), (Axelberg et al, 2008).

\subsection{Objectives and outline}

The objective of this research is to present a set of reliability criteria to evaluate recorded data used to assess power quality disturbances. The targets of the proposed methods are the data used in the determination of the network harmonic impedance and the identification of interharmonic sources. This chapter is structured as follows. Section 2 presents the data reliability criteria to be applied to both challenges. Section 3 presents the harmonic impedance determination problem and section 4 presents a network determination case study. Section 5 presents the interharmonic source determination problem and sections 6 and 7 present two case studies. Section 8 presents general conclusions and recommendations.

\section{Data reliability criteria}

This section is intended to present the main data reliability criteria proposed to be employed in the power quality applications addressed in this chapter. The criteria are applied in a slightly different manner to fit the nature of each problem. As it will be explained in this chapter, in the context of the network impedance estimation, the concern is $\Delta I(f)$ and $\Delta V(f)$ (the variation of the voltage or current), whereas for the case of interharmonic measurement, 
the concern is the value of $I(f)$ and $V(f)$. The reason for this will be explained in more detail in sections 3 and 4 , and at this point it is just important to keep in mind that the introduced criteria is applied in both cases, but with this slight difference.

\subsection{The energy level index}

As shown in (1), the network impedance determination is heavily reliant on $\Delta I(f)$, which is the denominator of the expression. Any inaccuracy on this parameter can result in great numerical deviance of the harmonic impedance accurate estimation. Therefore, the $\Delta I(f)$ energy level is of great concern. For this application, a threshold was suggested in (Xu et al, 2002) and is present in (2). If the calculated index is lower than the threshold level, the results obtained using these values are considered unreliable.

$$
I_{\text {threshold }}=\frac{\Delta I(f)}{\Delta I(60 \mathrm{~Hz})}>1 \% .
$$

Fig. 1 shows an example on how this criterion can be used. The energy level for $\Delta I(f)$ is compared with the threshold. For this case, frequencies around the $25^{\text {th }}$ harmonic order $(1500 \mathrm{~Hz})$ are unreliable according to this criterion.

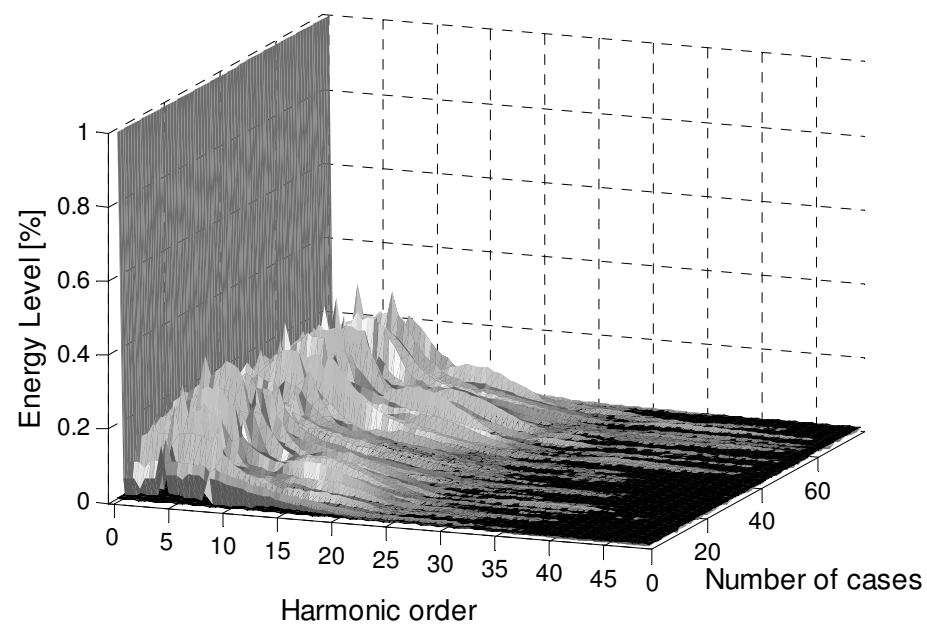

Fig. 1. Energy level of $\Delta I(f)$ seen in a three-dimensional plot

\subsection{Frequency-domain coherence index}

This index is used in the problem of the network impedance estimation, which relies on the transient portion of the recorded voltages and currents (section 3 presents the method in detail). The random nature of a transient makes it a suitable application for using the power density spectrum (Morched \& Kundur, 1987). The autocorrelation function of a random process is the appropriate statistical average, and the Fourier transform of the autocorrelation function provides the transformation from time domain to frequency domain, resulting in the power density spectrum. 
This relationship can be understood as a transfer function. The concept of transfer function using the power spectral method based on correlation functions can be treated as the result from dividing the cross-power spectrum by the auto-power spectrum. For electrical power systems, if the output is the voltage and the input is the current, the transfer function is the impedance response of the system (Morched \& Kundur, 1987). The degree of accuracy of the transfer function estimation can be assessed by the coherence function, which gives a measure of the power in the system output due to the input. This index is used as a data selection/rejection criterion and is given by

$$
\gamma_{V I}(f)=\frac{\left|P_{V I}(f)\right|^{2}}{P_{V V}(f) P_{I I}(f)},
$$

where $P_{V I}(f)$ is the cross-power spectrum of the voltage and current, which is obtained by the Fourier transform of the correlation between the two signals. Similarly, the auto-power spectrum $P_{V V}(f)$ and $P_{I I}(f)$ are the Fourier transforms of the voltage and current autocorrelation, respectively. By using the coherence function, it is typically revealed that areat deal of data falls within the category where input and output do not constitute a cause-effect relationship, which is the primary requirement of a transfer function.

\subsection{Time-domain correlation between interharmonic current and voltage spectra}

This index is used for the interharmonic source detection analysis, and is the time-domain twofold of the coherence index used for the harmonic system impedance. The criterion is supported by the fact that, if genuine interharmonics do exist, voltage and current spectra should show a correlation ( $\mathrm{Li}$ et al, 2001) because an interharmonic injection will result in a voltage across the system impedance, and therefore both the voltage and current should show similar trends at that frequency. As many measurement snapshots are taken, the variation over time of the interharmonic voltage and current trends are observed, and their correlation is analyzed. In order to quantify this similarity, the correlation coefficient is used (Harnett, 1982):

$$
r(i h)=\frac{n \sum_{i=1}^{n} I_{I H}(i) V_{I H}(i)-\sum_{i=1}^{n} I_{I H}(i) \sum_{i=1}^{n} V_{I H}(i)}{\sqrt{\left[n \sum_{i=1}^{n} I_{I H}^{2}(i)-\left(\sum_{i=1}^{n} I_{I H}(i)\right)^{2}\right]\left[n \sum_{i=1}^{n} V_{I H}^{2}(i)-\left(\sum_{i=1}^{n} V_{I H}(i)\right)^{2}\right]}},
$$

where $I_{I H}$ and $V_{I H}$ are the interharmonic frequency current and the voltage magnitudes of the $n$-snapshot interharmonic data, respectively. Frequencies showing the calculated correlation coefficient lower than an established threshold should not be reliable, as they may not be genuine interharmonics ( $\mathrm{Li}$ et al, 2001).

\subsection{Statistical data filtering and confidence intervals}

In many power quality applications, the measured data are used in calculations to obtain parameters that are subsequently used in further analyses. For example, in the network impedance estimation problem, the calculated resistance of the network may vary from 0.0060 to 0.0905 (ohms) in different snapshots (see Fig. 2). The resistance of the associated network is the average of these results. Most of the calculated resistances are between 0.0654 
and 0.0905 (ohms). Those values that are numerically distant from the rest of the data (shown inside the circles) may spoil the final result as those data are probably gross results. As per statistics theory, in the case of normally distributed data, 97 percent of the observations will differ by less than three times the standard deviation [14]. In the study presented in this chapter, the three standard deviation criterion is utilized to statistically filter the outlier data.

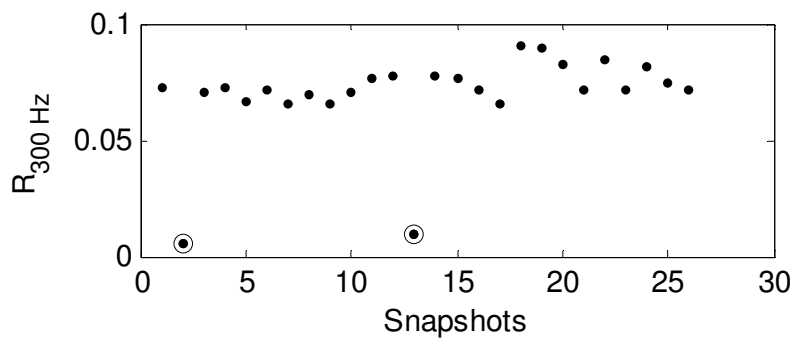

Fig. 2. Calculated $5^{\text {th }}$ harmonic resistance over a number of snapshots

In the example presented in Fig. 2, once the resistance of the network is achieved by averaging the filtered data, the confidence on the obtained results might be questioned. Instead of estimating the parameter by a single value, an interval likely to include the parameter is evaluated. Confidence intervals are used to indicate the reliability of such an estimate (Harnett, 1982). How likely the interval is to contain the parameter is determined by the confidence level or confidence coefficient. Increasing the desired confidence level will widen the confidence interval. For example, a 90\% confidence interval for the achieved resistance will result in a $0.0717 \pm 0.0055$ confidence interval. In the other words, the resistance of the network is likely to be between 0.662 and 0.772 (ohms) with a probability of $90 \%$.

Fig. 3 shows the calculated harmonic impedance of the network. Error bars are used to show the confidence intervals of the results. Larger confidence intervals present less reliable values. In this regard, the estimated resistance at $420 \mathrm{~Hz}$ is more reliable than its counterpart at $300 \mathrm{~Hz}$.

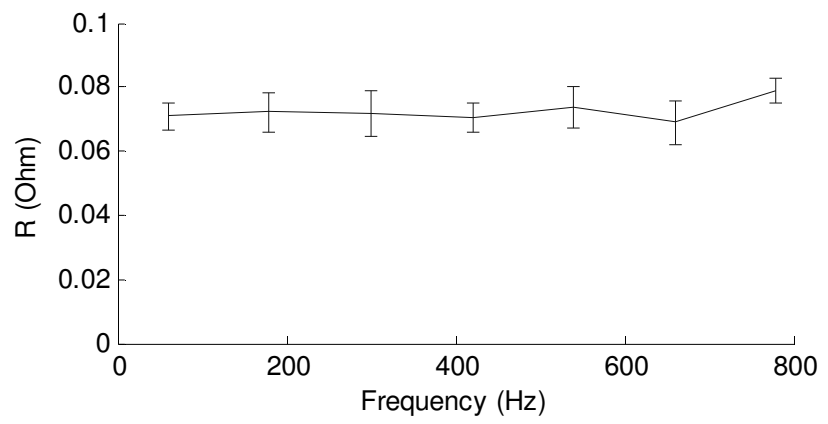

Fig. 3 . Selected $5^{\text {th }}$ harmonic resistance data showing confidence intervals. 


\subsection{Quantization error}

Quantization refers to the digitalization step of the data acquisition equipment. This value dictates the magnitude threshold that a measurement must have to be free of measurement quantization noise (Oppenheim \& Shafer, 1999). The A/D conversion introduces quantization error. The data collected are in the form of digital values while the actual data are in analog form. So the data are digitalized with an A/D converter. The error associated with this conversion is the quantization step. As the energy of current signals drops to a level comparable to that of quantization noises, the signal may be corrupted, and the data will, therefore, be unreliable. For this reason, if the harmonic currents are of magnitude lower than that of the quantization error, they should not be trusted. This criterion was developed as follows:

1. The step size of the quantizer is

$$
\Delta=V_{\text {in }} / 2^{n},
$$

where $n$ is the number of bits and $V_{i n}$ is the input range.

2. The current probe ratio is $k_{\text {probe, }}$ which is the ratio $\mathrm{V} / \mathrm{A}$.

3. Therefore, the step size in amperes is

$$
\Delta_{I}=\Delta / k_{\text {probe }} .
$$

4. Finally, the maximum quantization error will be half of the step size.

The input range, number of bits and current probe ratio will depend on the data acquisition equipment and measurement set up. The measurements presented later in this chapter are acquired by high-resolution equipment (NI-6020E - 100kbps, 12-bit, 8 channels). For the case of the system impedance estimation, equation (7) should hold true in order to generate reliable results for single-phase systems. This criterion is also used for $\Delta V(f)$ :

$$
|\Delta I(f)|>I_{\text {error }} .
$$

For the interharmonic case, the interharmonic current level $I(i h)$ is monitored rather than the $\Delta I(f)$ :

$$
|I(i h)|>I_{\text {error }} .
$$

\section{Network harmonic impedance estimation by using measured data}

The problem of the network harmonic impedance estimation by using measured data is explained in this section. Fig. 4 presents a typical scenario where measurements are taken to estimate the system harmonic impedance. Voltage and current probes are installed at the interface point between the network and the customer, called the point of common coupling (PCC). These probes are connected to the national instrument NI-6020E 12-bit data acquisition system with a $100 \mathrm{kHz}$ sampling rate controlled by a laptop computer. Using this data-acquisition system, 256 samples per cycle were obtained for each waveform. In Fig. 4 , the impedance $Z_{e q}$ is the equivalent impedance of the transmission and distribution lines, and of the step-down and step-up transformers. 


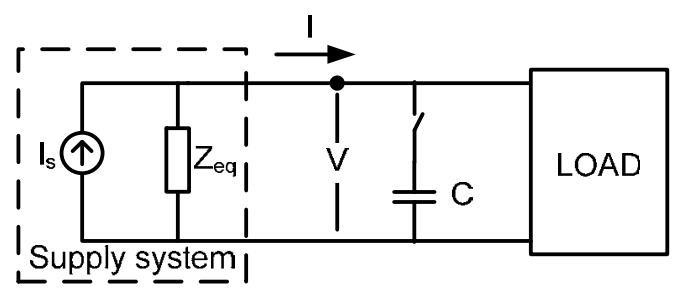

Fig. 4. Equivalent circuit for system impedance measurement.

Many methods that deal with measuring the harmonic impedance have been proposed and published (Xu et al, 2002), (Morched \& Kundur, 1987), (Oliveira et al, 1991). They can be classified as either invasive or non-invasive methods. Invasive methods are intended to produce a disturbance with energy high enough to change the state of the system to a different post-disturbance state. Such change in the system is necessary in order to obtain data records to satisfy (9) and (10), but low enough not to affect the operation of network equipment. The applied disturbance in the system generally causes an obvious transient in the voltage and current waveforms. The transient voltage and current data are used to obtain the impedance at harmonic frequencies. For the case presented in this chapter, the source of disturbance is a low voltage capacitor bank, but other devices can also be used, as explained in (Xu et al, 2002), (Morched \& Kundur, 1987), (Oliveira et al, 1991)

Therefore, the transient signal is extracted by subtracting one or more intact pre-disturbance cycles from the cycles containing the transient, as

$$
\begin{aligned}
& V_{\text {transient }}=V_{\text {disturbance }}-V_{\text {pre_disturbance }}=\Delta V, \\
& I_{\text {transient }}=I_{\text {disturbance }}-I_{\text {pre_disturbance }}=\Delta I .
\end{aligned}
$$

Finally, the network impedance is calculated by using

$$
Z_{e q}(h)=-\Delta V(h) / \Delta I(h) .
$$

\subsection{Characterization of the capacitor switching transient}

Traditionally, transients are characterized by their magnitude and duration. For the application of network impedance estimation, the harmonic content of a transient is a very useful piece of information. A transient due to the switching of a capacitor has the following characteristics (IEEE Std. 1159-1995):

Magnitude: up to 2 times the pre-existing voltage (assuming a previously discharged capacitor).

- Duration: From $0.3 \mathrm{~ms}$ to $50 \mathrm{~ms}$.

- $\quad$ Main frequency component: $300 \mathrm{~Hz}$ to $5 \mathrm{kHz}$.

The energization of the capacitor bank (isolated switching) typically results in a mediumfrequency oscillatory voltage transient with a primary frequency between 300 and $900 \mathrm{~Hz}$ and magnitude of 1.3-1.5 p.u., and not longer than two $60 \mathrm{~Hz}$ cycles. Fig. 5 shows typical transient waveforms and frequency contents due to a capacitor switching. For this case, the higher frequency components (except the fundamental component) are around $5^{\text {th }}$ to $10^{\text {th }}$ harmonic $(300-600 \mathrm{~Hz})$. 

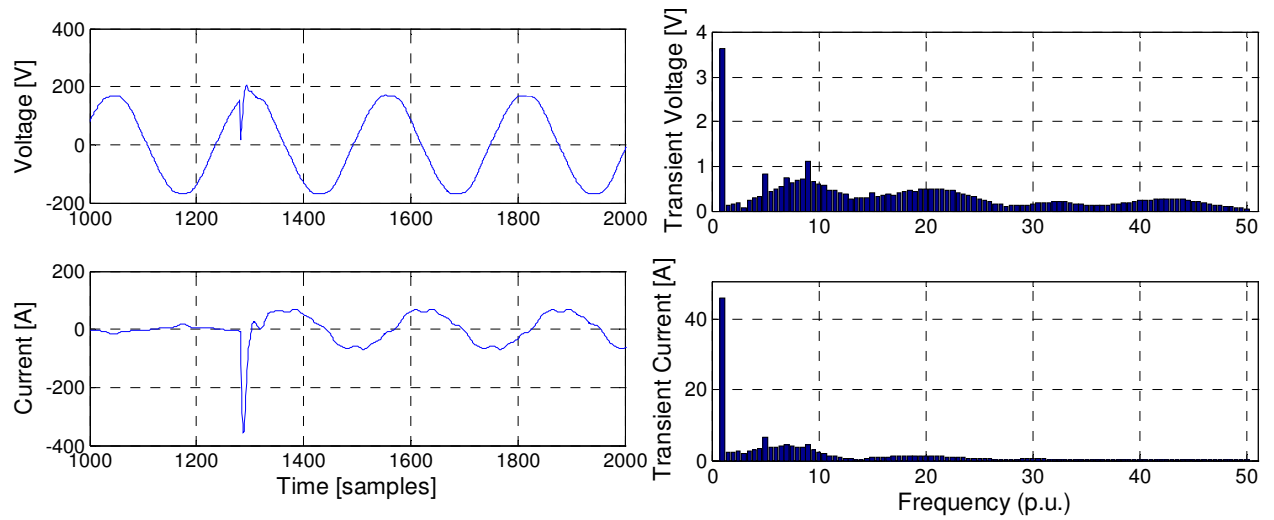

Fig. 5. Characterization of the transients resulting from a capacitor switching: (a) voltage and current waveforms during a disturbance, (b) Transient waveforms and frequency contents.

\subsection{Transient Identification}

The perfect extraction of the transient is needed for the present application. Several classification methods were proposed to address this problem, such as neural networks and wavelet transforms (Anis \& Morcos, 2002). Some other methods use criteria detection based on absolute peak magnitude, the principal frequency and the event duration less than 1 cycle (Sabin et al, 1999).

In this chapter, a simple approach is proposed to perform this task. It calculates the numerical derivative of the time-domain signals, and assumes that if a transient occurred, this derivative should be higher than 10. As a result, the numerical algorithm monitors the recorded waveforms and calculates the derivatives at each data sample; when this derivative is higher than 10, it can be concluded that a capacitor switching occurred.

\section{Impedance measurement case study}

More than 120 field tests have been carried out in most of the major utilities in Canada (in the provinces of British Columbia, Ontario, Alberta, Quebec, Nova Scotia and Manitoba), and a representative case is presented in this section. Over 70 snapshots (capacitor switching events) were taken at this site. Using the techniques described in section II, the impedance results were obtained and are presented in Fig. 6 . This figure shows that in the range of $1200-1750 \mathrm{~Hz}$ there is an unexpected behavior in both components of the impedance. A resonant condition may be the reason of this sudden change. However, it might be caused by unreliable data instead. Further investigation is needed in order to provide a conclusion for this case.

Based on extensive experience acquired by dealing with the collected data, the following thresholds were proposed for each index:

- $\quad$ Energy level: $\Delta I(f)>1 \%$ and $\Delta V(f)>1 \%$.

- Coherence: $r(f) \geq 0.95$.

- Standard deviation: $\delta \geq 0.5$.

- Quantization error: $\Delta I(f)>0.0244 \mathrm{~A}$. 


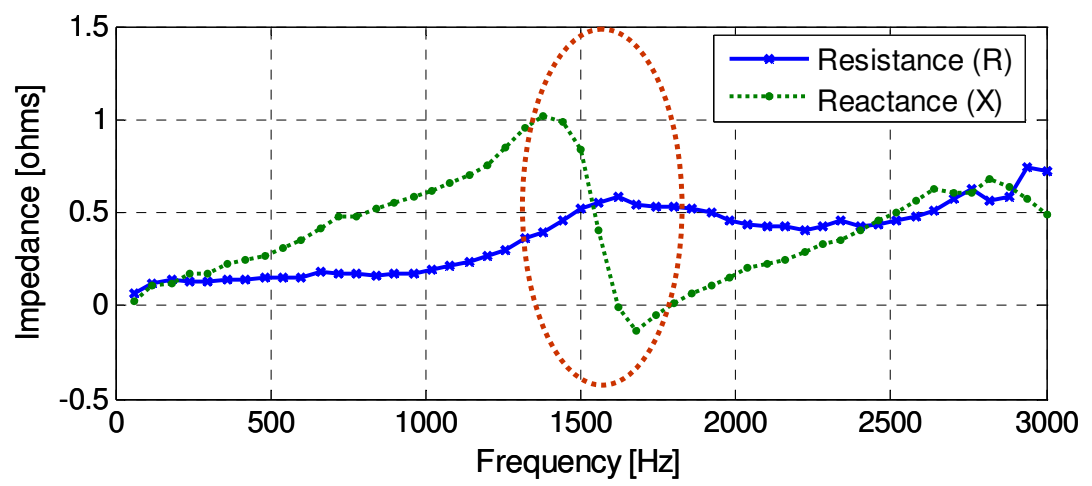

Fig. 6. Harmonic impedance for a sample field test used in the case study.

As the reliability criteria are applied, it is useful to define the following ratio of success:

$$
\text { Ratio }=\text { Successfull cases } / \text { Total cases } \times 100 \%,
$$

where each case is one data snapshot taken at each site.

Fig. 7 shows the success rate of cases for each index in function of frequency. Fig. 7a. also shows that the application of this index will affect $\Delta I$ much more than for $\Delta V$, since the latter is acquired using voltage probes, which are inherently much more reliable. Since the impedance measurement is calculated from the ratio $-\Delta V / \Delta I$, the voltage threshold is applied to the denominator and is therefore less sensitive, as shown in ( $\mathrm{Xu}$ et al, 2002). Fig. $7 \mathrm{~b}$. shows that the coherence index does not reveal much information about reliability of the measurements; however it provides an indicator of the principal frequency of the transient signals, highlighted in the dotted circle. The standard deviation results presented in Fig. 7c. show that the impedances measured at frequencies between 1260 and $2000 \mathrm{~Hz}$ are very spread out and are, therefore, unreliable. The same situation occurs for frequencies above $2610 \mathrm{~Hz}$. These results agree with those presented in Fig. 7a. for the threshold used for $\Delta I$. Fig. $7 \mathrm{~d}$. shows that the quantization is not a critical issue and the measurements taken in the field are accurate enough to overcome quantization noises. However the low quantization values, especially for current, are of lower values for the unreliable ranges presented in Fig. 7a. and Fig. 7c.

\section{Interharmonic source determination}

In harmonic analysis, many polluters are usually present in a power distribution system for each harmonic order because power system harmonics always occur in fixed frequencies, i.e., integer multiples of the fundamental frequency. All harmonic loads usually generate all harmonic orders, and therefore, it is common to try to determine the harmonic contribution of each load rather than the harmonic sources. As opposed to harmonics, interharmonics are almost always generated by a single polluter. This property of interharmonics can be explained as follows. 

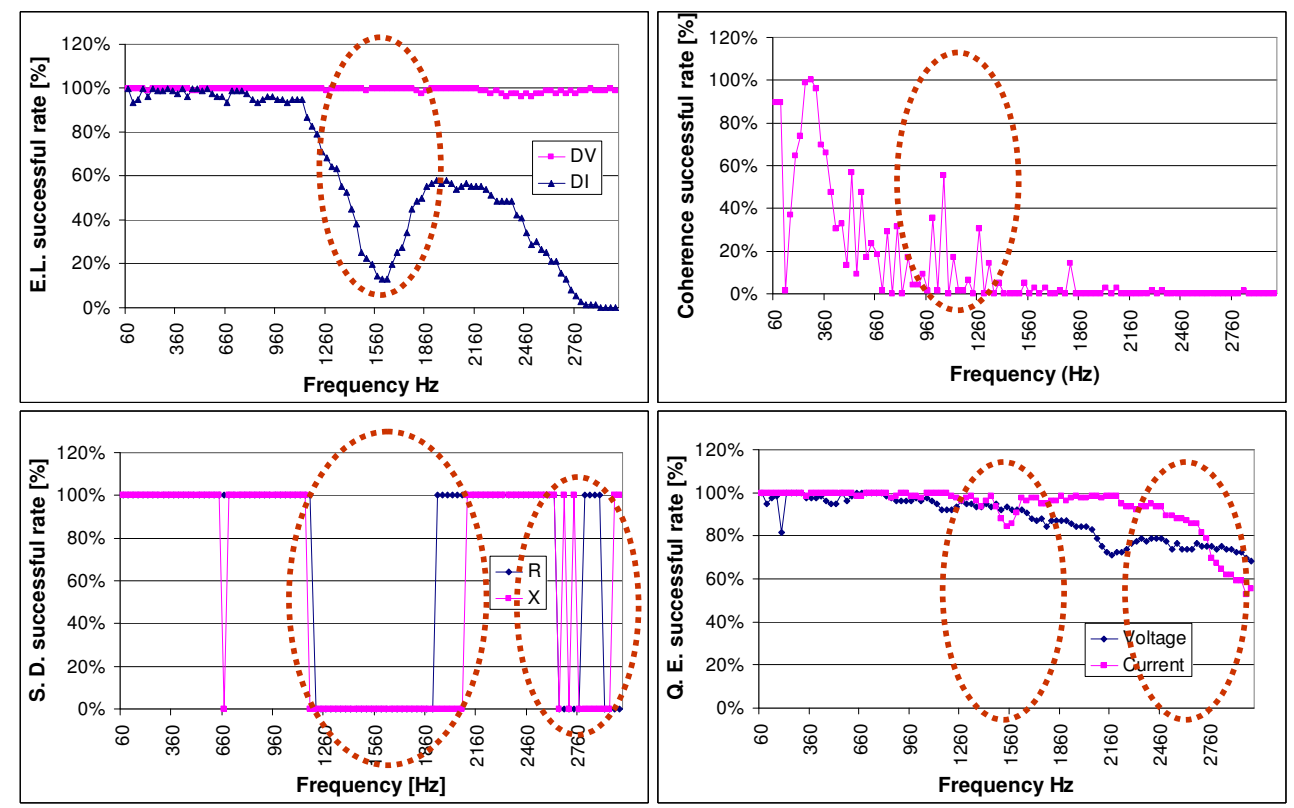

Fig. 7. Indices in function of frequency: (a) energy level, (b) coherence, (c) standard deviation, (d) quantization error.

The main interharmonic sources are adjustable speed drives (ASDs) with a $p_{1}$-pulse rectifier and a $p_{2}$-pulse inverter and periodically varying loads such as arc furnaces. Their interharmonic generation characteristics can be expressed as in (12) for ASDs (Yacamini, 1996) and (13) for periodically varying loads (IEEE Task Force, 2007), respectively:

$$
f_{I H}=\left|\left(p_{1} m \pm 1\right) f \pm p_{2} n f_{z}\right|, \quad m=0,1,2 \ldots ; \quad n=1,2,3 \ldots,
$$

where $f$ and $f_{\mathrm{z}}$ are the fundamental and drive-operating frequency.

$$
f_{I H}=\left|f \pm n f_{v}\right|, \quad n=1,2,3 \ldots,
$$

where $f_{v}$ is the load-varying frequency. According to equations (12) and (13), the interharmonic frequency depends on many factors such as the number of pulses of the converter and inverter, the drive-operating frequency, or the load-varying frequency. Therefore, the same frequency of interharmonics is rarely generated by more than one customer.

Based on the above analysis, for interharmonic source determination, the analysis can be limited to the case of a single source for each of the interharmonic components. The most popular method currently being used to identify the interharmonic sources is based on the active power index. Fig. 8 helps to explain the power direction method. For this problem, the polluter side is usually assumed to be represented by its respective Norton equivalent circuit. Fig. 8 shows two different scenarios at the metering point between the upstream (system) and the downstream (customer) sides. Fig. 8a and Fig. 8b show the case where the interharmonic components come from the upstream side and the downstream side, respectively. The circuits presented in Fig. 8 are used for each frequency. 


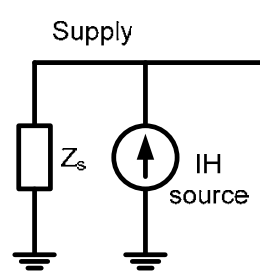

a. IH comes from Supply side

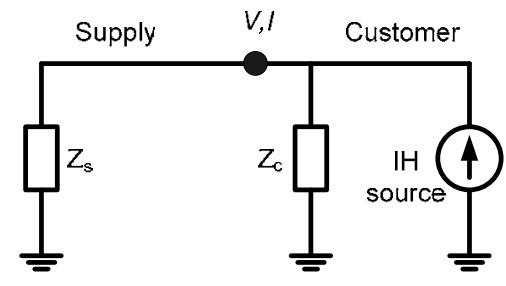

b. IH comes from Customer side

Fig. 8. Determination of interharmonic source - two different scenarios.

The interharmonic active power can be obtained from the voltage and current measurements at a metering point as

$$
P_{I H}=\operatorname{Re}\left\{V_{I H} \times I_{I H}^{*}\right\}=\left|V_{I H}\right|\left|I_{I H}\right| \cos \left(\phi_{I H}\right),
$$

where $\left|V_{I H}\right|$ and $\left|I_{I H}\right|$ are the interharmonic voltage and current magnitudes, respectively, and $\varphi_{I H}$ is the angle displacement between the interharmonic voltage and current.

The conclusion of the power direction method, therefore, is the following (Kim et al, 2005), (Axelberg, 2008):

- $\quad$ If $P_{I H}>0$, the interharmonic component comes from the upstream side.

- If $P_{I H}<0$, the interharmonic component comes from the downstream side.

If this criterion is extended to a multi-feeding system like that shown in Fig. 9, the interharmonic source for each interharmonic can be identified. In such a case, monitoring equipment should be placed at each feeder suspected of injecting interharmonics into the system. For the system side measurements (point A), if the measured $P_{I H}>0$, the interharmonic component comes from the system. For the customer side measurements (points $\mathrm{B}$ and $\mathrm{C}$ ), if the measured $P_{I H}<0$, the interharmonic component comes from the measured customer.

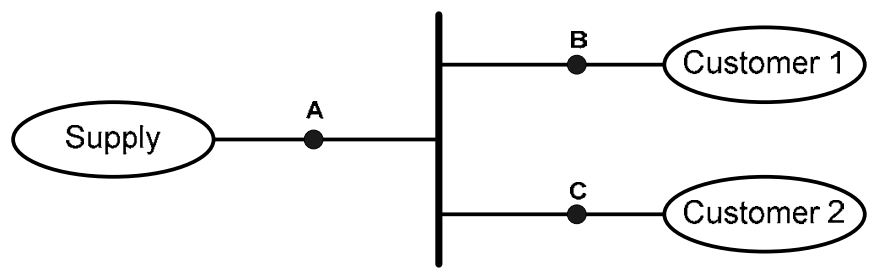

Fig. 9. System diagram for locating the interharmonic source.

As a given interharmonic frequency has only one source, the power direction method (in theory) could always reveal the interharmonic source correctly. In reality, as the active power of the interharmonics is typically very small, the measured data may not be reliable, so this index may not provide reliable conclusions. On the other hand, the angle $\varphi_{I H}$ can be very close to either $\pi / 2$ or $-\pi / 2$, oscillating around these angles because of measurement errors, and resulting in the measured active power index swinging its sign and potentially causing misjudgment. The drifting nature of interharmonics in frequency and the supply fundamental frequency variation also influence this inaccuracy. 


\section{Interharmonic source determination case study \#1}

The case study presented in this section illustrates the worst known effect of the interharmonics at present, which is the interference with control signals at the power line. The Automatic Meter Reading devices (AMR) of a utility company of the province of Alberta had experienced difficulties to receive inbound signals in a large oilfield extraction area. Utility engineers suspected that this interference could be caused by the presence of interharmonics. Field measurements were carried out at the substation feeder and at large customers that were suspected to be interharmonic polluters. The arrangement for the field measurement is shown in Fig. 10. The measured feeder supplies three customers, codenamed Customer 1, Customer 2 and Customer 3. These customers operate large oil extracting drives. The measurements were done through potential transformers and current transformers (PTs and CTs). The data were acquired for a period of two days, taking automatic snapshots of 5 seconds at every minute. The hardware utilized was a National Instruments NI-DAQ6020E, which operates at $100 \mathrm{~kb} / \mathrm{s}$ and has 8-channel capability. With this sampling rate, the recorded waveforms contained 256 points per cycle.

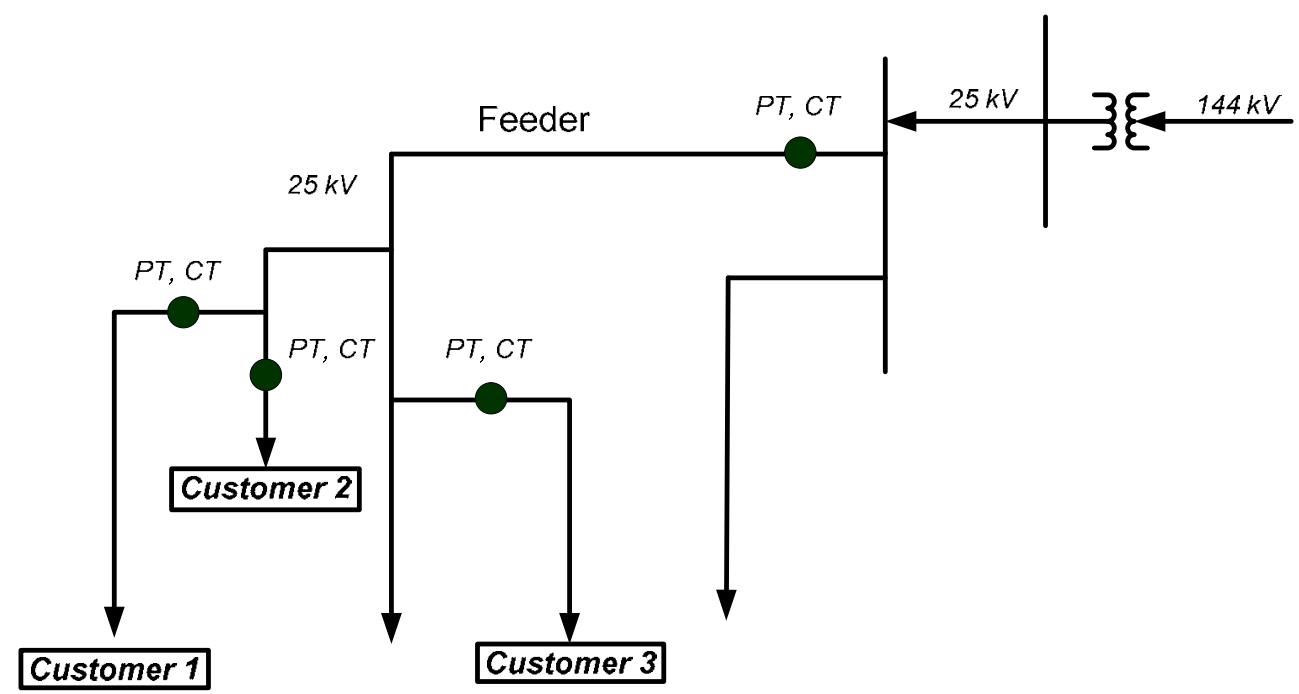

Fig. 10. Field measurement locations at the measured area

After processing all data snapshots taken at the four locations, a spectrum contour plot measured at the feeder is drawn in order to obtain the frequencies of the interharmonic components that are present in this system. Fig. 11 shows the contour plot of the data recorded at the feeder during one of the measured days. From this figure, it can be seen that there are four dominant interharmonic components, which seem to be two pairs: at around $228 \mathrm{~Hz}$ and $348 \mathrm{~Hz}$, and $264 \mathrm{~Hz}$ and $384 \mathrm{~Hz}$. These components drift a little in frequency due to the change of the drive operation conditions, but they exist inside a narrow frequency range. 


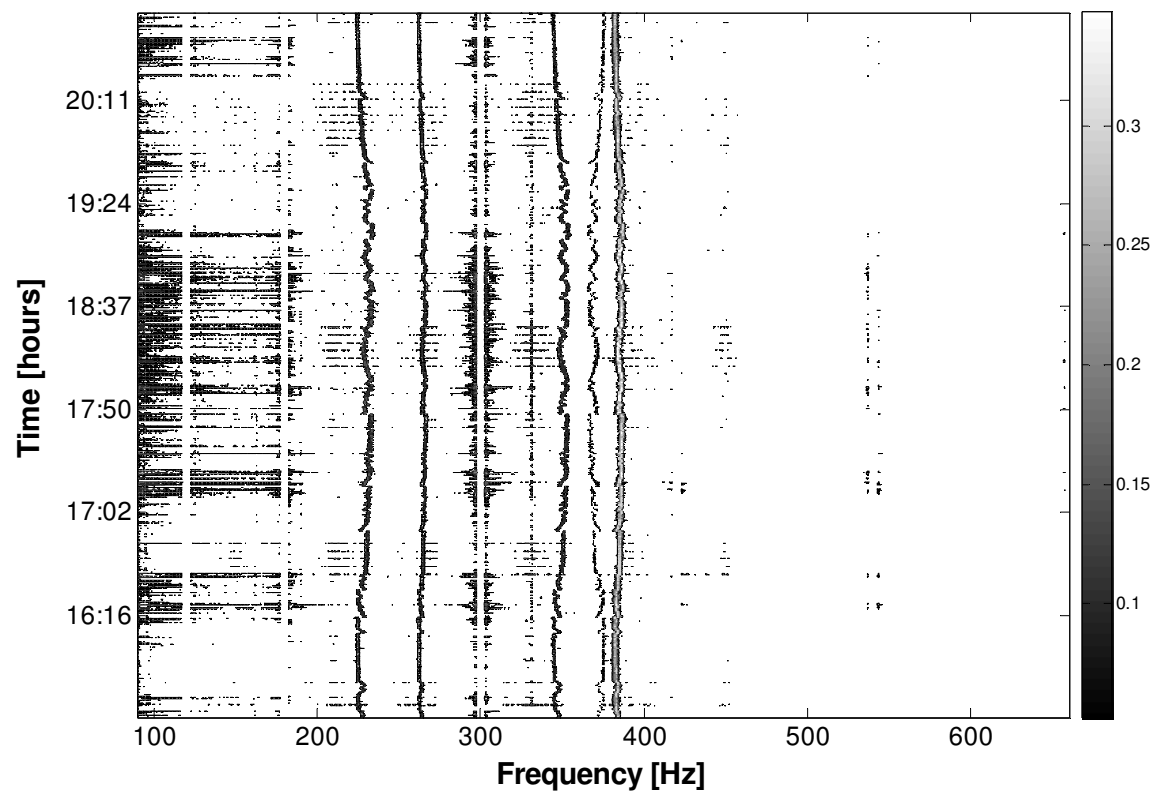

Fig. 11. Contour plot of the interharmonic data recorded at the feeder

The active power index was monitored at the three loads. This is shown in Fig. 12-Fig. 15. The system was observed to be fairly balanced, and therefore only the power in phase A is shown. By looking into these figures, one would conclude that Customer 2 is the source of interharmonics $228 \mathrm{~Hz}, 348 \mathrm{~Hz}$ and $384 \mathrm{~Hz}$, whereas Customer 3 is the source of interharmonics $264 \mathrm{~Hz}$ and $348 \mathrm{~Hz}$. As explained in equation (2), it is almost impossible that an interharmonic component is generated by two sources at the same time. Furthermore, after deeper investigation, it is shown that this apparent identification of the interharmonic polluters is incorrect, and the reliability criteria proposed in this chapter is useful in aiding the researcher to drawing correct conclusions.

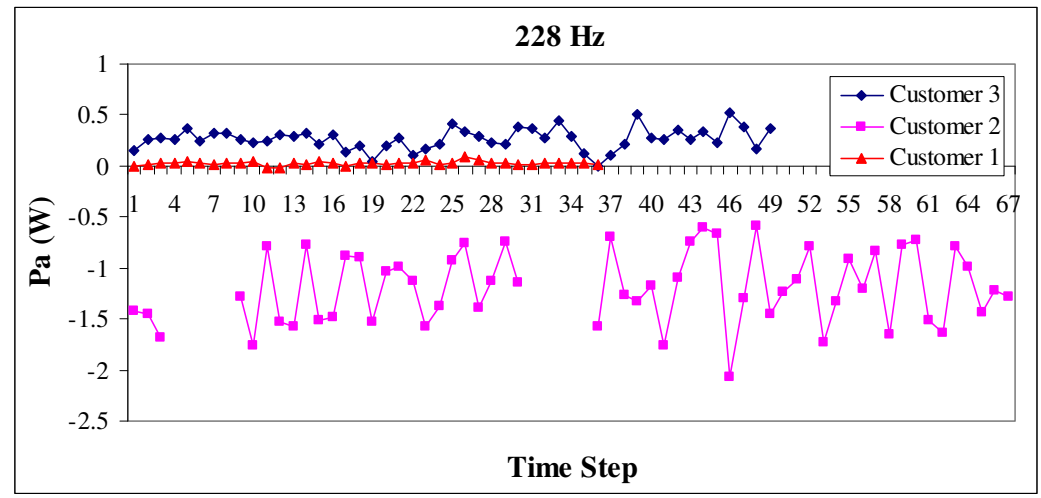

Fig. 12. Active power at the loads for $f_{I H}=228 \mathrm{~Hz}$ 


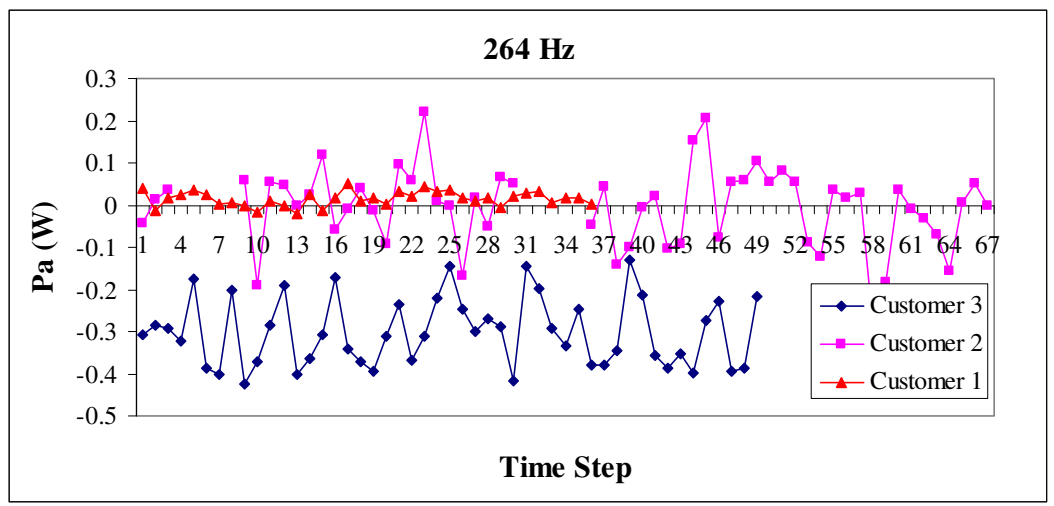

Fig. 13. Active power at the loads for $f_{I H}=264 \mathrm{~Hz}$

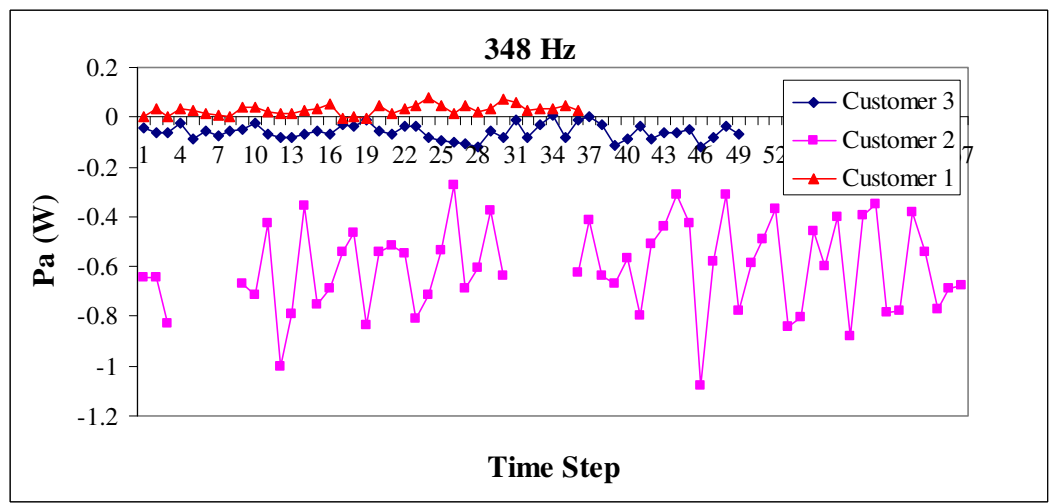

Fig. 14. Active power at the loads for $f_{I H}=348 \mathrm{~Hz}$

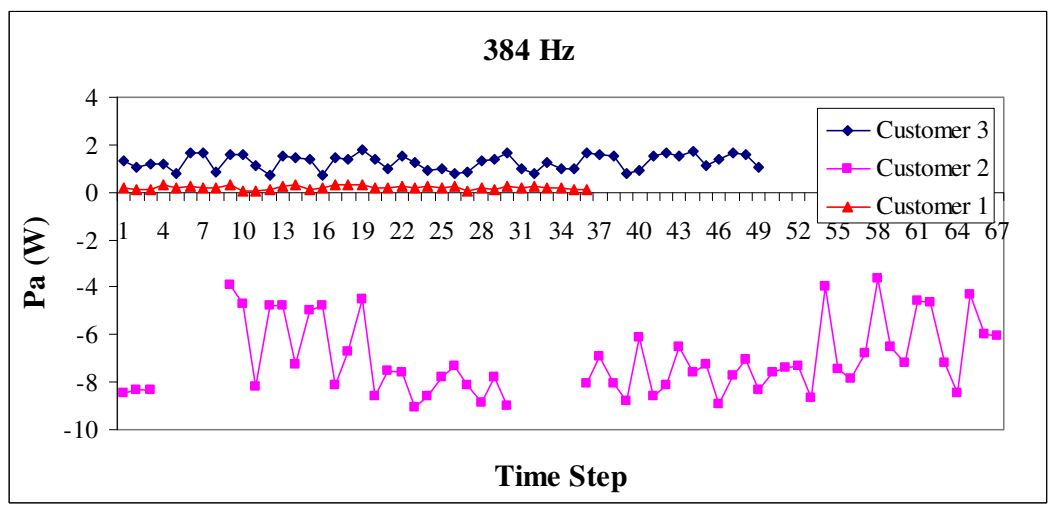

Fig. 15. Active power at the loads for $f_{I H}=384 \mathrm{~Hz}$ 


\subsection{Applying the reliability criteria}

The first step to utilize the reliability criteria is to obtain the percentage of snapshots containing measurements with energy levels above the quantization error. This result for the case study is shown in Table 1. According to this criterion, the interharmonic currents measured at the feeder may be unreliable because they are too low as compared to the current fundamental component. This fact does not mean that the measured interharmonics are harmless, but simply that 12 bits of the data acquisition device are not enough to accurately measure their magnitudes. As for the loads, all data are reliable, except those of Customer 3 at $348 \mathrm{~Hz}$.

\begin{tabular}{|c|c|c|c|c|}
\hline IH freq (Hz) & Feeder & Customer 1 & Customer 2 & Customer 3 \\
\hline \hline 228 & 0.00 & 19.44 & 100.00 & 91.84 \\
\hline 264 & 0.00 & 0.00 & 77.19 & 81.63 \\
\hline 348 & 0.00 & 0.00 & 3.51 & 0.00 \\
\hline 384 & 0.00 & 100.00 & 100.00 & 100.00 \\
\hline
\end{tabular}

Table 1. Percentage of Snapshots with Energy Level Higher than Quantization Step

The interharmonic voltage-current correlation for all the locations is calculated as well, and shown in Table 2. The results obtained for the feeder show that its measurements may not reliable. For the loads, it can be seen that the correlation is generally high, except for that of Customer 2 at $264 \mathrm{~Hz}$.

\begin{tabular}{|c|c|c|c|c|}
\hline IH freq (Hz) & Feeder & Customer 1 & Customer 2 & Customer 3 \\
\hline \hline $\mathbf{2 2 8}$ & 0.68 & 0.98 & 0.96 & 0.98 \\
\hline $\mathbf{2 6 4}$ & 0.31 & 0.96 & 0.59 & 0.92 \\
\hline $\mathbf{3 4 8}$ & 0.55 & 0.96 & 0.92 & 0.96 \\
\hline $\mathbf{3 8 4}$ & 0.77 & 0.99 & 0.98 & 0.97 \\
\hline
\end{tabular}

Table 2. V-I Correlation Coefficient (\%)

The other reliability criteria are also used but do not add much information to the conclusions to be drawn in Table 3, which summarizes the reliability at each frequency for each location.

\begin{tabular}{|c|c|c|c|c|}
\hline IH freq (Hz) & Feeder & Customer 1 & Customer 2 & Customer 3 \\
\hline \hline $\mathbf{2 2 8}$ & No & Yes & Yes & Yes \\
\hline $\mathbf{2 6 4}$ & No & No & No & Yes \\
\hline $\mathbf{3 4 8}$ & No & No & Yes & No \\
\hline $\mathbf{3 8 4}$ & No & Yes & Yes & Yes \\
\hline
\end{tabular}

Table 3. Reliability Summary

Table 4 shows the average of calculated active power at the feeder and at the loads (phase A). Note that the shaded cells are the ones that should not be trusted. 


\begin{tabular}{|c|c|c|c|c|}
\hline $\begin{array}{c}\text { IH Freq } \\
\mathbf{( H z )}\end{array}$ & $\begin{array}{c}\mathbf{P}(\mathbf{W}) \\
\text { Feeder }\end{array}$ & $\begin{array}{c}\mathbf{P}(\mathbf{W}) \\
\text { Customer 1 }\end{array}$ & $\begin{array}{c}\mathbf{P}(\mathbf{W}) \\
\text { Customer 2 }\end{array}$ & $\begin{array}{c}\mathbf{P}(\mathbf{W}) \\
\text { Customer 3 }\end{array}$ \\
\hline \hline $\mathbf{2 2 8}$ & -0.52 & 0.09 & -3.53 & 0.72 \\
\hline $\mathbf{2 6 4}$ & -1.14 & 0.07 & 0.13 & -0.75 \\
\hline $\mathbf{3 4 8}$ & -1.05 & 0.08 & -1.98 & -0.14 \\
\hline $\mathbf{3 8 4}$ & -6.34 & 0.58 & -23.5 & 3.64 \\
\hline
\end{tabular}

Table 4. Active Power Results for the Feeder and Customers

\subsection{The $V_{I H} I_{I H}$ angle displacement}

The power direction method relies on the information about the difference between the interharmonic voltage and current angles. If this difference is close to 90 or 270 degrees, the cosine of this difference will be very close to zero. For interharmonics of very low magnitude, the power may oscillate around zero, because the angle displacement usually exhibit lots of fluctuation due to measurement inaccuracies. Therefore, caution is needed when using the power direction method, since it is too sensitive to this angle.

In the present case study, such fluctuation happens for interharmonics $264 \mathrm{~Hz}$ and $348 \mathrm{~Hz}$. Furthermore, the active power results shown in Fig. 13 and Fig. 14 reveal that the power level is very low. This was also shown in Table 1, which revealed that many snapshots contain data with very low energy level. For these frequencies, the conclusions drawn using the power direction method cannot be trusted. A final conclusion about these frequencies will be provided in next subsection by using the theory of interharmonic pairing.

\subsection{The Interharmonic phase sequence characteristics}

Using the phase sequence characteristics of interharmonics, it can be verified that interharmonics $228 \mathrm{~Hz}$ and $348 \mathrm{~Hz}$ of this case study are one pair, and interharmonics 264 $\mathrm{Hz}$ and $384 \mathrm{~Hz}$ are another pair. From (12), it can be estimated that the drives' frequencies are $48 \mathrm{~Hz}$ and $54 \mathrm{~Hz}$, and that the number of pulses of the inverter is $p_{2}=6$. From this equation, it was also identified that $228 \mathrm{~Hz}$ and $264 \mathrm{~Hz}$ are negative sequence, whereas 348 $\mathrm{Hz}$ and $384 \mathrm{~Hz}$ are positive sequence, as explained in (Zhang et al, 2005). Therefore, all parameters in (12) can be estimated as

$$
\begin{aligned}
& -228=60-6 \times 48, \\
& -364=60-6 \times 54, \\
& +348=60+6 \times 48, \\
& +384=60+6 \times 54 .
\end{aligned}
$$

The same conclusion about the sequence is verified through analyzing the measurements: the symmetrical components of the interharmonic currents are calculated and one of them (positive-, negative- or zero-sequence) is observed to match the phase currents (the system is fairly balanced).

Since it is clear that the source of two interharmonic frequencies of a pair is the same, it is confirmed that Table 4 shows some inconsistencies: Customer 3 cannot be the source of interharmonic $264 \mathrm{~Hz}$ unless it is also the source of interharmonic $384 \mathrm{~Hz}$. It was, however, determined that Customer 2 is the source of interharmonic $384 \mathrm{~Hz}$. This inconsistency for Customer 2 undermines the credibility of the conclusions taken at this frequency. It is not possible that interharmonic $264 \mathrm{~Hz}$ comes from both Customer 3 and Customer 2. Finally 
the possibility that Customer 3 is the source of the interharmonic $264 \mathrm{~Hz}$ can be ruled out because this frequency is a pair of $384 \mathrm{~Hz}$, which was generated from Customer 2.

\section{Interharmonic source determination case study \#2}

In a second case, interharmonic problems were experienced in another oilfield area of Alberta, Canada. Measurements were taken at three customers, codenamed Customer 1, Customer 2, and Customer 3, which were operating big oil extraction ASD drives and were suspected interharmonic sources. The system diagram is shown in Fig. 16. The measurements at the metering points revealed that the interharmonic detected frequencies were present throughout the system.

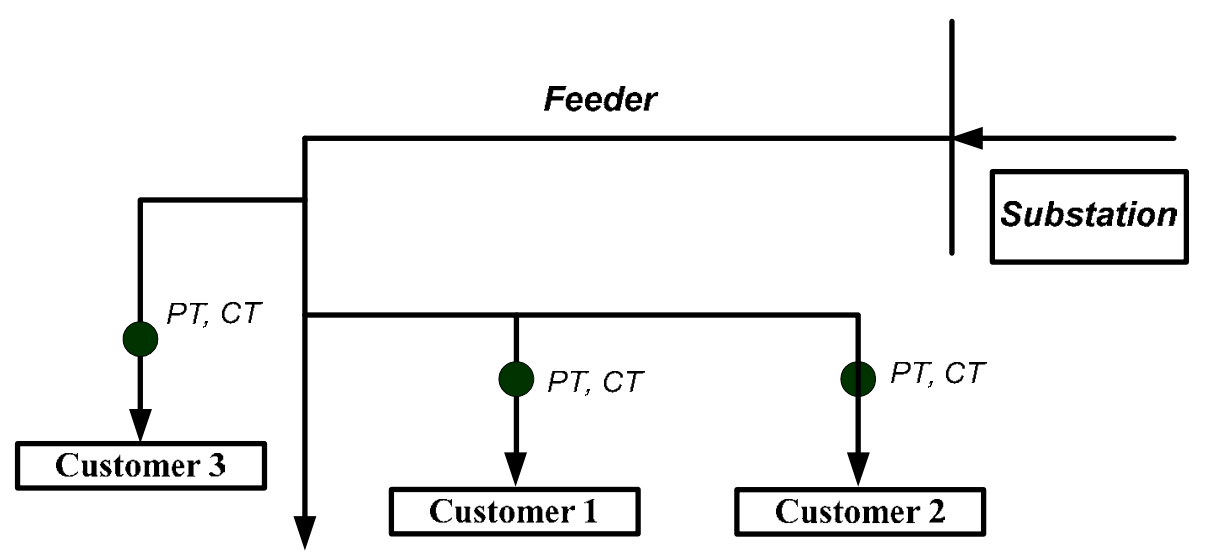

Fig. 16. Field measurement locations at system \#2

Fig. 17 shows a sample contour plot of the spectrum calculated for the three Customers' currents in order to obtain the frequencies of the interharmonic components present in this system. Two main interharmonics are identified: $151 \mathrm{~Hz}$ and $271 \mathrm{~Hz}$.

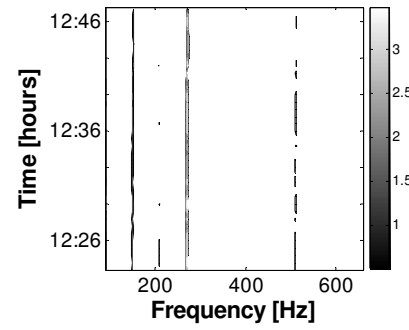

(a)

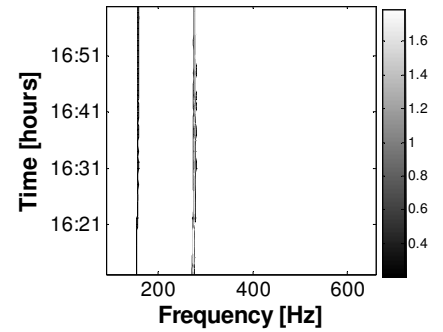

(b)

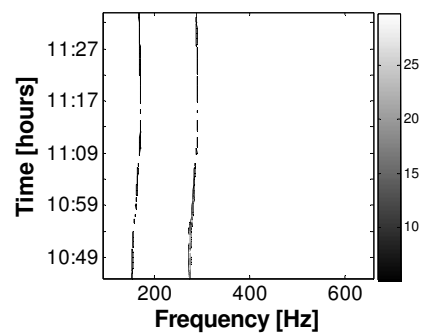

(c)

Figure 17. Contour plot of the interharmonic data recorded at the three Customers (phase A): (a) customer 1, (b) customer 2, (c) customer 3.

\subsection{Criteria for determining the reliability of the data}

Table 5 shows the percentage of reliable snapshots obtained by using the quantization error criterion. Only snapshots with an energy level higher than the quantization error could be 
used. All the data were reliable in this case due to the high magnitude of the interharmonic components.

\begin{tabular}{|c|c|c|c|}
\hline IH freq (Hz) & Customer 1 & Customer 2 & Customer 3 \\
\hline \hline $\mathbf{1 5 1} \mathbf{H z}$ & 100 & 100 & 100 \\
$\mathbf{2 7 1} \mathbf{~ H z}$ & 100 & 100 & 100 \\
\hline
\end{tabular}

Table 5. Reliable Snapshots [\%] According to the Quantization Error Criterion for System \#2

Table 6 shows the correlation results for the locations, revealing that the interharmonic voltage and current had a high degree of correlation at the three customer loads.

\begin{tabular}{|l|l|l|l|}
\hline IH freq (Hz) & Customer 1 & Customer 2 & Customer 3 \\
\hline \hline $\mathbf{1 5 1} \mathbf{H z}$ & 0.93 & 0.88 & 0.98 \\
$\mathbf{2 7 1} \mathbf{~ H z}$ & 1.00 & 1.00 & 1.00 \\
\hline
\end{tabular}

Table 6. Correlation Results for System \#2

\subsection{Results}

The power direction results are shown in Table 7. In this case, the data was deemed reliable by all reliability criteria.

\begin{tabular}{|c|c|c|}
\hline Location of measurements & IH frequency [Hz] & $\operatorname{Sign}\left(\boldsymbol{P}_{I H}\right)$ \\
\hline \hline \multirow{2}{*}{ Customer 1} & 151 & + \\
& 271 & + \\
\hline \multirow{2}{*}{ Customer 2 } & 151 & + \\
& 271 & + \\
\hline \multirow{2}{*}{ Customer 3 } & 151 & - \\
& 271 & - \\
\hline
\end{tabular}

Table 7. Power Direction (at Interharmonic Frequencies) Results for System \#2

The information for $\operatorname{sign}\left(P_{I H}\right)$ reveals that the $\operatorname{sign}\left(P_{I H}\right)$ of Customer 3 is negative, so that Customer 3 was the source. In this case, the angle displacement between the voltage and current was not observed to fluctuate at around $\pm \Pi / 2$ radians. Therefore, the power direction method can be used with full confidence.

\section{Conclusions}

This chapter investigated the reliability of the data used for the power quality disturbances assessment. The main applications were to estimate the network harmonic impedance and to determine the interharmonic source. A set of criteria to state about the data reliability was presented. They consisted in proposing thresholds for the following parameters:

- Frequency-domain coherence;

- Time-domain correlation;

- Quantization error;

- Standard deviation; 
For the network impedance estimation application, it has been found that the energy level for $\Delta I(f)$ is a useful data filtering, but for $\Delta V(f)$ it has been found that it does not really make any difference. The Coherence index does not reveal much information about unreliable measurements but clearly identifies the principal frequency components of the transient. Analyses carried out on the quantization error level demonstrated that quantization noise is substantial for high frequencies and that the measurements taken are not significantly affected by quantization noises. The suggested thresholds for data rejection used were determined through extensive experience with handling data and provided more accurate and dependable results. These thresholds can be further adjusted as new data are analyzed and experience is built to improve the engineering judgment.

For the interharmonic source detection, the power direction method is very sensitive to the typical low energy level of the interharmonic currents. It was observed that this low energy level affects the displacement angle between voltage and current, which may prevent using the method to conclude about some frequencies. Interharmonic pairing theory was used to draw a final conclusion for the smaller-magnitude interharmonics in the case study. For the higher magnitude interharmonics, the power direction method could be used with the confidence provided by the reliability criteria.

\section{Acknowledgments}

The author gratefully acknowledges the financial support provided by Hydro One to partially cover the publication of this chapter and also their encouragement into improving this research work.

The author also expresses his gratitude towards Mr. Edwin Enrique Nino from ATCO electric for providing the several data sets of the network harmonic impedance collected in many Canadian utility sites, for processing the data and providing the presented results. Thanks are also extended to Mr. Hooman Mazin for providing part of the statistical analysis used in the network harmonic impedance data filtering application.

Finally, the author expresses his appreciation to Prof. Wilsun $\mathrm{Xu}$ for his supervision, technical contributions and high-level advices.

\section{References}

Anis, W. R. \& Morcos, M. M. (2002). Artificial Intelligence and Advanced Mathematical Tools for Power Quality Applications: A Survey, IEEE Trans. Power Delivery, vol. 17, no. 2.

Axelberg, P. G. V., Bollen, M. J., Gu, I. Y. (2008). Trace of Flicker Sources by Using the Quantity of Flicker Power, IEEE Trans. Power Delivery, vol. 23, no. 1, pp. 465-471.

Ghartemani, M. K. \& Iravani, M. R. (2005). Measurement of Harmonics/Interharmonics of Time-Varying Frequencies, IEEE Trans. Power Delivery, vol. 20, no. 1, pp. 23-31.

Harnett, D. L. (1982). Statistical Methods, Third Edition, Addison Wesley.

IEEE Std. 519-1992 (1993) IEEE Recommended Practices and Requirements for Harmonic Control in Electrical Power Systems

IEEE Std. 1159-1995. (1995). IEEE Recommended Practice for Monitoring Electric Power Quality.

IEEE Task Force on Harmonics Modeling and Simulation. (2007). Interharmonics: Theory and Measurement, IEEE Trans. Power Delivery, vol. 22, no. 4.

IEEE Interharmonic Task Force. (1997). Cigre 36.05/CIRED 2 CC02 Voltage Quality Working Group, Interharmonics in Power Systems. 
Johnson, R. A. \& Wichern, D. W. (2007). Applied Multivariate Statistical Analysis, Sixth edition, Pearson Prentice Hall.

Kim, T., Powers, E. J., Grady, W. M., Arapostathis, A. (2005). Real and Reactive Power Analysis for Interharmonics, Proceedings of the IEEE Electric Ship Technologies Symposium, pp. 244-247.

Kimbark, E. (1971). Direct Current Transmission (vol. 1), John Wiley \& Sons

Li, C., Xu, W., Tayjasanant, T. (2001). Interharmonics: Basic Concepts and Techniques for their Detection and Measurement, Electric Power Syst. Res., vol. 66, pp. 39-48.

Morched, A. S. and Kundur, P. (1987). Identification and Modeling of Load Characteristics at High Frequencies, IEEE Trans. Power Systems, vol. PWRS-2, no. 1, pp. 153-160.

Nassif, A. B, Yong, J., Mazin, H., Wang, X., Xu, W., (2010a). An Impedance-Based Approach for Identifying Interharmonic Sources. IEEE Transactions on Power Delivery, vol. 26, no. 1, pp. 333-340.

Nassif, A. B, Nino, E. E., Mazin, H. (2009). On the Reliability of Real Measurement Data for Assessing Power Quality Disturbances, Proceedings of the IEEE PES General Meeting.

Nassif, A. B., Yong, J., Xu, W. (2010b). Interharmonics: Signaling processing issues and applications, Proceedings of the IEEE PES General Meeting.

Oppenheim, A. V. and Schafer, R. W. (1999). Discrete-Time Signal Processing, 2nd Ed. (Prentice Hall: Upper Saddle River, NJ).

Oliveira, A., Oliveira, J. C., Resende J. W., Miskulin M. S. (1991). Practical approaches for AC system harmonic impedance measurements, IEEE Trans. Power Delivery, vol. 6, pp. 1721-1726.

Robert, A. \& Deflandre, T. (1997). Guide for assessing the network harmonic impedances, Proceedings of the Joint CIGRE/CIRED 97, 2-5 June 1997, Conference Publication No. 438.

Sabin, D. D., Grebe, T. E., Brooks, D. L., Sundaram A. (1999), Rules-based Algorithm for Detecting Transient Overvoltages due to Capacitor Switching and Statistical Analysis of Capacitor Switching in Distribution Systems, Proceedings of the IEEE Transmission and Distribution Conference, vol. 2, pp. 630-635.

Xu, W., Ahmed, E. E., Zhang, X. and Liu, X. (2002). Measurement of Network Harmonic Impedances: Practical Implementation Issues and Their Solutions, IEEE Trans. Power Delivery, pp 210-216 vol. 17, no. 1.

Yacamini, R. (1996). Power System Harmonics: Part 4 Interharmonics, IEE Power Eng. J., pp. 185-193.

Zhang, D., Xu W., Liu, Y. (2005). On the Phase Sequence Characteristics of Interharmonics, IEEE Trans. Power Delivery, vol. 20, no. 4, pp. 2563-2569. 


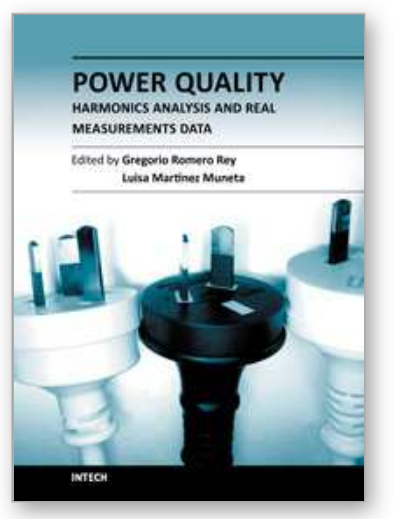

\author{
Power Quality Harmonics Analysis and Real Measurements Data \\ Edited by Prof. Gregorio Romero
}

ISBN 978-953-307-335-4

Hard cover, 278 pages

Publisher InTech

Published online 23, November, 2011

Published in print edition November, 2011

Nowadays, the increasing use of power electronics equipment origins important distortions. The perfect AC power systems are a pure sinusoidal wave, both voltage and current, but the ever-increasing existence of nonlinear loads modify the characteristics of voltage and current from the ideal sinusoidal wave. This deviation from the ideal wave is reflected by the harmonics and, although its effects vary depending on the type of load, it affects the efficiency of an electrical system and can cause considerable damage to the systems and infrastructures. Ensuring optimal power quality after a good design and devices means productivity, efficiency, competitiveness and profitability. Nevertheless, nobody can assure the optimal power quality when there is a good design if the correct testing and working process from the obtained data is not properly assured at every instant; this entails processing the real data correctly. In this book the reader will be introduced to the harmonics analysis from the real measurement data and to the study of different industrial environments and electronic devices.

\title{
How to reference
}

In order to correctly reference this scholarly work, feel free to copy and paste the following:

Alexandre Brandao Nassif (2011). On the Reliability of Real Measurement Data for Assessing Power Quality Disturbances, Power Quality Harmonics Analysis and Real Measurements Data, Prof. Gregorio Romero (Ed.), ISBN: 978-953-307-335-4, InTech, Available from: http://www.intechopen.com/books/power-quality-harmonicsanalysis-and-real-measurements-data/on-the-reliability-of-real-measurement-data-for-assessing-powerquality-disturbances

\section{INTECH}

open science | open minds

\section{InTech Europe}

University Campus STeP Ri

Slavka Krautzeka 83/A

51000 Rijeka, Croatia

Phone: +385 (51) 770447

Fax: +385 (51) 686166

www.intechopen.com

\section{InTech China}

Unit 405, Office Block, Hotel Equatorial Shanghai

No.65, Yan An Road (West), Shanghai, 200040, China 中国上海市延安西路65号上海国际贵都大饭店办公楼 405 单元

Phone: +86-21-62489820

Fax: +86-21-62489821 
(C) 2011 The Author(s). Licensee IntechOpen. This is an open access article distributed under the terms of the Creative Commons Attribution 3.0 License, which permits unrestricted use, distribution, and reproduction in any medium, provided the original work is properly cited. 